\title{
Potential and restrictions of photocentrifugation for determining the emulsion stability of melted spreadable processed cheese
}

\author{
Wolfgang Hoffmann ${ }^{1}$
}

Received: 27 March 2015 / Revised: 23 July 2015 / Accepted: 27 July 2015 /

Published online: 16 August 2015

(C) INRA and Springer-Verlag France 2015

\begin{abstract}
A previous study had shown that the method of photocentrifugation could be adapted to monitor emulsion stability of melted spreadable processed cheese (PC) with low content of emulsifying salts (ES). The present study continued the experiments with higher ES content exploring the potential and restrictions of this new approach. The PC containing $40 \%$ fat in dry matter and 1.0 or $1.9 \% w / w$ ES was manufactured for 5-19 min at $82{ }^{\circ} \mathrm{C}$ and three different rotational speeds of the cutter. Light transmission was measured during centrifugation of the melted $\mathrm{PC}$ in thin cuvettes at $60{ }^{\circ} \mathrm{C}$. The transmission profiles were used to characterize emulsion stability. Fat distribution was measured for better interpretation of the centrifugation results. An increase in transmission to $\geq 20 \%$ occurred after different periods of centrifugation at $1200 \times g$. Samples with $1.0 \% \mathrm{w} / \mathrm{w}$ ES showed different particle movements during centrifugation for $150 \mathrm{~min}$. Polydisperse creaming, sedimentation, and distinct zone sedimentation were identified, the latter allowing the calculation of characteristic sedimentation velocities. The PC with $1.9 \%$ w/w ES manufactured at a cutter speed of $3000 \mathrm{rpm}$ for $5 \mathrm{~min}$ required the maximum acceleration of $2150 \times \mathrm{g}$ to achieve measurable transmission after $195 \mathrm{~min}$, corresponding to 291 days under normal gravity. These results show the high sensitivity of photocentrifugation proving even little physical changes of the PC matrix. However, this sensitivity restricts the applications to melted spreadable and suboptimal emulsified products.
\end{abstract}

Keywords Emulsion stability $\cdot$ Photocentrifugation $\cdot$ Sedimentation $\cdot$ Spreadable processed cheese

Wolfgang Hoffmann

wolfgang.hoffmann@mri.bund.de

1 Department of Safety and Quality of Milk and Fish Products, Max Rubner-Institut, Hermann-Weigmann-Straße 1, D-24103 Kiel, Germany 


\section{Introduction}

Physical properties of spreadable processed cheese (PC) during or after production have been analyzed by different procedures. Torque profiles were measured in a farinograph during the manufacture of cheese analogues (El-Bakry et al. 2010). Dimitreli et al. (2005) and Dimitreli and Thomareis (2008) manufactured PC inside the vessel of a capillary tube viscometer and measured the viscosity before solidification. Lee et al. (2003) transferred PC from a lab cooker to a rheometer and analyzed the viscosity profile and microstructural changes. Uniaxial compression and texture profile analysis were applied after manufacturing, usually at $15-20^{\circ} \mathrm{C}$ (Weiserová et al. 2011; Bunka et al. 2014; Nagyová et al. 2014; Hladká et al. 2014). A temperature sweep in a rheometer covered 20 to $90{ }^{\circ} \mathrm{C}$ and was performed at low frequency and deformation (Shirashoji et al. 2010; Guinee and O'Kennedy 2012; Schatz et al. 2014).

Continuous measurement of light transmission through PC-filled cuvettes during centrifugation is a quite different approach, and results cannot be correlated with those of all other methods quoted. Photocentrifugation measures even smallest physical changes and particle movements allowing a very sensitive characterization of emulsion stability. Hoffmann and Schrader (2015) used photocentrifugation to monitor emulsion stability of spreadable processed cheese with a low content of emulsifying salts (ES). Insufficient fat emulsification and a heterogeneous casein matrix could be well illustrated. The present study continued these experiments increasing the content of ES up to 1.0 and $1.9 \% w / w$ ES. The particular sensitivity of photocentrifugation might result in additional insights in emulsion stability of spreadable PC. However, this sensitivity might restrict the application to a limited range of such products. A measurement of fat distribution should make the interpretation of the centrifugation results easier.

\section{Materials and methods}

\subsection{Ingredients and manufacture of spreadable processed cheese}

Composition and manufacture of the spreadable PC corresponded to the samples produced and analyzed by Hoffmann and Schrader (2015). The spreadable PC contained Edam cheese (foil-ripened blocks, $\sim 56 \%$ dry matter (DM), $\geq 40 \%$ fat in DM, pH 5.25-5.30, 9 weeks maturity), butter ( $\geq 82 \%$ fat), skim milk powder (SMP) for DM adjustment, potassium hydroxide for $\mathrm{pH}$ adjustment, and a blend of ES (JOHA S9, ICL Food Specialties, Ladenburg, Germany) containing sodium polyphosphate and sodium monophosphate. JOHA S9 has a medium capacity for ion exchange and creaming, and a $\mathrm{pH}$ value of 9.0 in $1 \%$ aqueous solution.

The PC consisted of $56 \mathrm{wt} \%$ Edam cheese, $2.2 \% w / w$ butter, $\sim 39 \% w / w$ condensate of injected steam, and additional water for DM adjustment. The remaining ingredients were either 1.0\% $w / w$ JOHA S9, $0.21 \% w / w \mathrm{KOH}$, and 1.7\% $w / w$ SMP, or $1.9 \% w / w$ JOHA S9, $0.08 \% w / w \mathrm{KOH}$, and $1.0 \% w / w$ SMP. The mixtures were designed to reach target values of $36.5 \% \mathrm{DM}, 40 \%$ fat in $\mathrm{DM}$, and $\mathrm{pH} 5.9$. Each mixture was produced in triplicate.

Batches were processed in a lab cooker (UM/SK 5; Stephan, Hameln, Germany). The premixed blend was heated to $82{ }^{\circ} \mathrm{C}$ within 3 min using direct steam injection. During heating, the cutter velocity was kept at a constant speed $(1000,1500$, or 
$3000 \mathrm{rpm})$. At the target temperature, steam injection was stopped and stirring continued at the same speed. After 5, 7, 11, and 19 min of processing, the cooker was briefly opened and an aliquot was quickly cooled and stored at $5{ }^{\circ} \mathrm{C}$ until analyzing. The emulsion stability of these samples was determined after 8, 28, and 56 days. DM (according to VDLUFA 2003), $\mathrm{pH}$ value (measured directly with a piercing electrode), and the particle size distribution were analyzed after 1 day.

\subsection{Particle size distribution and emulsion stability}

Selected PC samples were diluted only with water (1:10) and slowly stirred at $38{ }^{\circ} \mathrm{C}$ for 15 min using a magnetic stirrer. This procedure differed from the method of Lee et al. (2004). They added EDTA to split fat clusters by calcium sequestration. The measurement in this study should include still existing clusters after dilution. Light microscopic images of all analyzed samples confirmed the presence of such aggregates. Preliminary trials resulted in reproducible data showing an averaged variation coefficient of $4.55 \%$. The diluted samples were homogeneous, and no sedimentation was visible until the end of measurement. The fat distribution of the PC was analyzed using a laser diffraction spectrophotometer (Coulter LS 230; Beckman Coulter, Krefeld, Germany). The average volume-moment diameters $\left(d_{4,3}\right)$ of fat globules and clusters were calculated using the refraction indices according to Borcherding et al. (2008). As stated previously, all PC mixtures were manufactured in triplicate. Each of these samples were also measured in triplicate and results averaged.

Emulsion stability was analyzed using the LUMiSizer 611 (LUM, Berlin, Germany). Vials containing PC were heated in a $65^{\circ} \mathrm{C}$ water bath for $20 \mathrm{~min}$, and two thin $(2 \mathrm{~mm})$ rectangular cuvettes filled with $\sim 0.4 \mathrm{ml}$ of the PC. The cuvettes were capped and centrifuged at $3000 \mathrm{rpm}(\sim 1200 \times g)$ or $4000 \mathrm{rpm}(\sim 2150 \times g)$ for up to $300 \mathrm{~min}$ at $60{ }^{\circ} \mathrm{C}$. Every $30 \mathrm{~s}$, transmission profiles were captured at $870 \mathrm{~nm}$ throughout the cell. For a simple determination of phase separation and destabilization phenomena, an instability index was calculated by the included software (SepView 6.0; LUM). The dimensionless index was quantified by the clarification at a given separation time, divided by the maximum clarification (Detloff et al. 2013). All cuvettes were photographed after centrifugation.

\subsection{Statistical analysis}

One-way analysis of variance (ANOVA) was applied of data for particle size distribution $(n=9)$ using the general linear model using SigmaPlot 11 statistical software (Systat Software, San Jose, CA, USA). All differences were considered as statistically significant at $p \leq 0.05$. In the case of significant differences, Tukey pairwise comparisons were performed. Results of Fig. 1 are expressed as mean \pm standard deviation of triplicate trials measured in duplicate. ANOVA and Tukey were also applied.

\section{Results and discussion}

\subsection{Particle size distribution}

A cutter speed of $1000 \mathrm{rpm}$ during the manufacture of PC with 1.0 and $1.9 \% \mathrm{w} / \mathrm{w}$ JOHA S9 resulted in an average $d_{4,3}$ of 8 to $15 \mu \mathrm{m}$ (Table 1). The water-diluted 


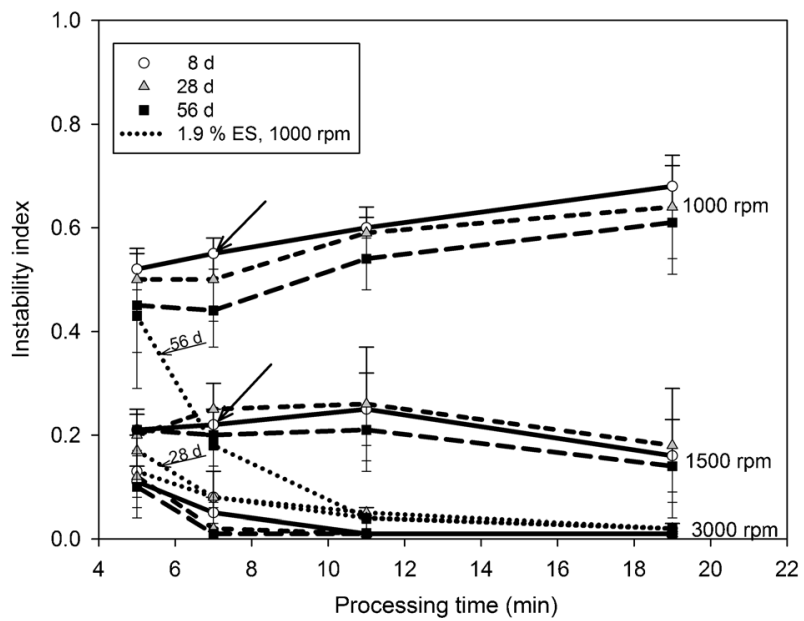

Fig. 1 Effect of manufacturing conditions and storage period $\left(8,28\right.$, and 56 days at $\left.5{ }^{\circ} \mathrm{C}\right)$ on the instability index after photocentrifugation $(1200 \times \mathrm{g}, 100 \mathrm{~min})$ of spreadable PC with $1.0 \% \mathrm{w} / \mathrm{w}$ ES manufactured at 1000 , 1500 , or $3000 \mathrm{rpm}$ cutter speed and of PC with $1.9 \%$ ES manufactured at $1000 \mathrm{rpm}$ for 5, 7, 11, and $19 \mathrm{~min}$. Values are mean \pm error bars of three experiments measured in duplicate each. Arrows indicate results illustrated in Fig. 2

samples exhibited no visible casein aggregates under the light microscope. Thus, all casein was finely dispersed, and particle size measurements covered only single fat globules or fat clusters. A cutter speed of $3000 \mathrm{rpm}$ yielded a smaller $d_{4,3}$. The effect of processing time was significant $(p<0.05)$ at this speed and $1.9 \% w / w$ ES (Table 1$)$. Nineteen minutes of processing resulted in a narrow monomodal fat distribution and $d_{4,3}$ of only $1 \mu \mathrm{m}$. Therefore, these manufacturing conditions and the ES content seemed to be sufficient for complete emulsification of the milk fat originating from the Edam cheese and butter. These results were confirmed by other studies indicating that the structure typically consists of fat globules between 1 and $10 \mu \mathrm{m}$ (summarized by Guinee et al. 2004). Rayan et al. (1980) showed that, as the processing time for PC increases, the size of fat globules decreases, indicating a stronger emulsification. Results of Garimella Purna et al. (2006) demonstrated that, at high mixing speeds, PC contains fat globules with a smaller mean diameter.

Table 1 Effect of manufacturing conditions on volume-mean diameter $\left(d_{4,3}\right)$ in spreadable processed cheese with 1.0 and $1.9 \%$ w/w ES processed at 1000 or $3000 \mathrm{rpm}$ cutter speed for 5-19 min

Superscripts with different letters within the same column are significantly different $(p<0.05)$. The results are expressed as means \pm standard deviation of three experiments measured in triplicate each

\begin{tabular}{cll}
\hline Processing time (min) & $d_{4,3}$ at $1.0 \% \mathrm{w} / w$ ES & $d_{4,3}$ at $1.9 \% w / w$ ES \\
\hline 1000 rpm cutter speed & \\
5 & $14.71 \pm 4.25^{\mathrm{a}}$ & $10.65 \pm 0.94^{\mathrm{a}}$ \\
7 & $12.00 \pm 2.15^{\mathrm{a}}$ & $10.88 \pm 1.76^{\mathrm{a}}$ \\
11 & $10.78 \pm 2.97^{\mathrm{a}}$ & $9.53 \pm 1.62^{\mathrm{a}}$ \\
19 & $10.49 \pm 4.00^{\mathrm{a}}$ & $8.03 \pm 2.06^{\mathrm{a}}$ \\
$3000 \mathrm{rpm}$ cutter speed & \\
5 & $5.64 \pm 1.34^{\mathrm{a}}$ & $2.88 \pm 0.20^{\mathrm{a}}$ \\
7 & $3.96 \pm 0.27^{\mathrm{a}}$ & $2.25 \pm 0.27^{\mathrm{a}}$ \\
11 & $4.08 \pm 0.38^{\mathrm{a}}$ & $1.51 \pm 0.07^{\mathrm{b}}$ \\
19 & $3.56 \pm 0.53^{\mathrm{a}}$ & $1.02 \pm 0.03^{\mathrm{c}}$ \\
\hline
\end{tabular}




\subsection{Photocentrifugation}

\subsubsection{Processed cheese with $1.0 \% \mathrm{w} / \mathrm{w}$ emulsifying salts}

Figure 1 depicts the instability index for PC with 1.0\% w/w ES after $100 \mathrm{~min}$ of photocentrifugation at $1200 \times \mathrm{g}$. An effect of cutter speed during manufacturing, but not of processing time or storage period between manufacture and analysis, was clearly detected. The instability index at the three cutter speeds differed significantly $(p<0.05)$ at processing times of 7, 11 and 19 min independently of the storage period. The products manufactured at $3000 \mathrm{rpm}$ for at least $7 \mathrm{~min}$ remained stable during centrifugation and exhibited only a small, if measurable, increase in transmission and the instability index. This corresponded to the results of fat distribution. Obviously, the volume-mean diameter of the fat globules was one suitable indicator for emulsion stability. Smaller fat globules may contribute to the overall continuity of the matrix by acting as fillers, resulting in a product with a more reinforced structure (Brickley et al. 2007). The underlying transmission profiles of the two results marked in Fig. 1 are presented in Fig. 2. Photos of the cuvettes after $150 \mathrm{~min}$ of centrifugation illustrate a distinct phase separation. Both photos show coalesced fat on the PC surface and a transparent zone in the middle of the cuvette. The development of this zone is described by the transmission profiles.

After $40 \mathrm{~min}$ of centrifugation, corresponding to 33 days under normal gravity $(1 \times g)$, the transmission of the PC manufactured at $1000 \mathrm{rpm}$ cutter speed increased to $\geq 20 \%$ (Fig. 2 a). The level of $20 \%$ transmission was also used by van Lent et al. (2008) and Tobin et al. (2010) to evaluate particle movements. A broken line marks this point in the cuvette (at $114.7 \mathrm{~mm}$ ). The area toward the cuvette bottom (at $130 \mathrm{~mm}$ ) exhibits mainly zone sedimentation, where most particles moved with the same sedimentation rate despite differences in particle mass. Toward the end of centrifugation, the distance between consecutive profiles gradually narrowed and the resistance against further compression increased as the casein network became more compacted. The mean sedimentation velocity between 95 and $105 \mathrm{~min}$ of centrifugation was equivalent to $66 \mu \mathrm{m} \cdot \mathrm{day}^{-1}$ at $1 \times \mathrm{g}$ but decreased to $39 \mu \mathrm{m}$. day $^{-1}$ between 145 and $150 \mathrm{~min}$.

The course of the transmission profiles also illustrates slight creaming above the broken line to the meniscus of the PC (at $106 \mathrm{~mm}$ ) and polydisperse sedimentation. In contrast to the coalesced fat layer at the top of the centrifuged PC, the creaming is an evidence of the movement of larger emulsified fat globules or fat clusters. Roughly horizontal and parallel sections of the transmission profiles represent polydisperse sedimentation. These particles moved individually with different velocities according to their size and density. The zone of high transmission after $150 \mathrm{~min}$ had an extension of $7.28 \mathrm{~mm}$ in the cuvette and is equivalent to approximately $30 \%$ of the filling level.

The centrifugation of the PC manufactured at $1500 \mathrm{rpm}$ cutter speed resulted in similar appearance of the cuvettes and the transmission profiles (Fig. 2b). Three different particle movements were observed during centrifugation. Transmission $\geq 20 \%$ was not measured until 75 min of centrifugation, corresponding to 62.5 days under normal gravity. The mean zone sedimentation velocity between 95 and $105 \mathrm{~min}$ was $54 \mu \mathrm{m}$.day ${ }^{-1}$ at $1 \times g$ and $42 \mu \mathrm{m}$.day ${ }^{-1}$ between 145 and $150 \mathrm{~min}$. The transparent zone had a range of $5.76 \mathrm{~mm}$ after $150 \mathrm{~min}$. In contrast to the PC manufactured at 

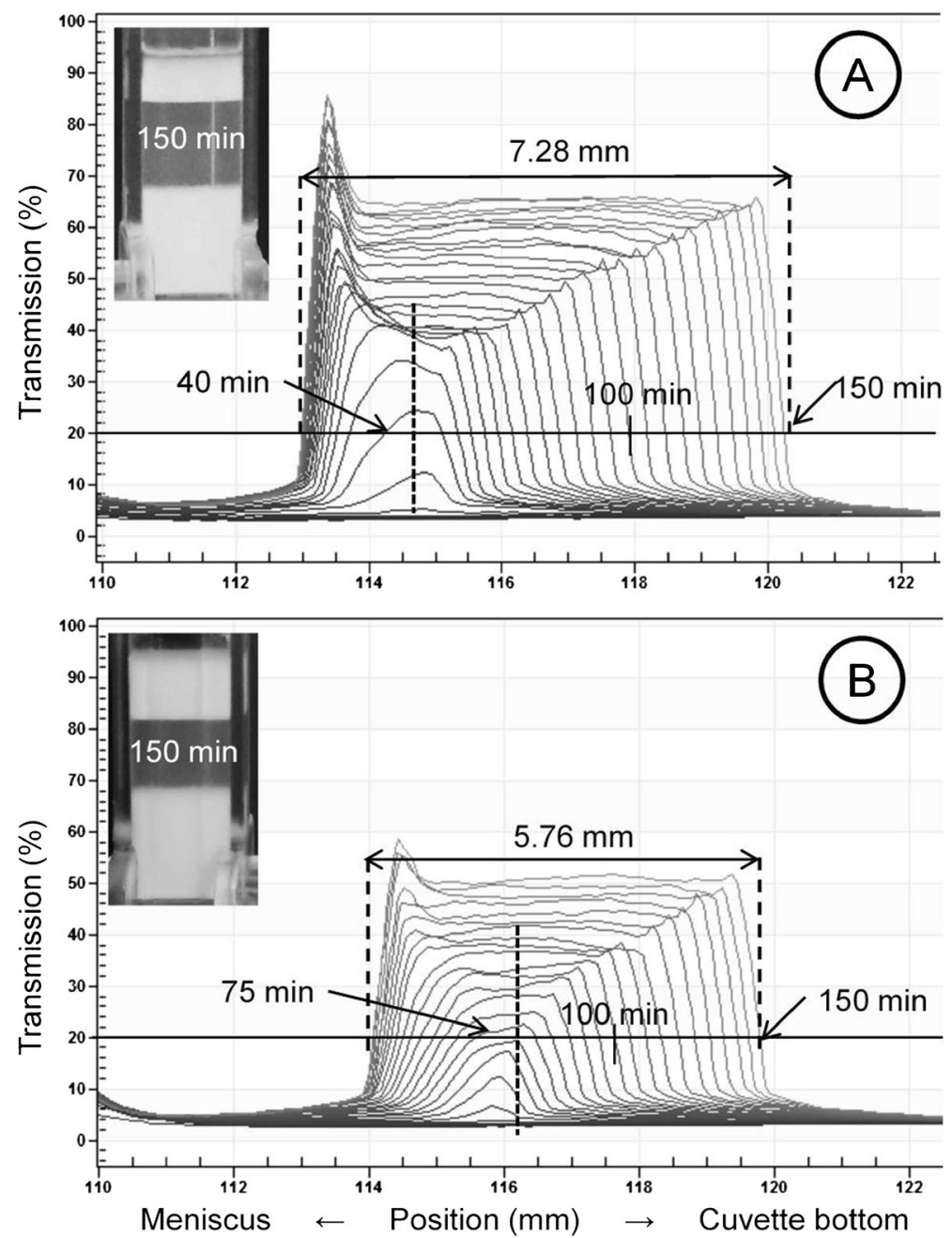

Fig. 2 Transmission profiles obtained every $5 \mathrm{~min}$ during photocentrifugation $(1200 \times \mathrm{g}, 150 \mathrm{~min})$ of processed cheese-filled cuvettes at $60{ }^{\circ} \mathrm{C}$. The processed cheese contained $1.0 \% \mathrm{w} / \mathrm{w}$ emulsifying salts and was kept for 8 days at $5{ }^{\circ} \mathrm{C}$. a $1000 \mathrm{rpm}$ cutter speed for $7 \mathrm{~min}$; b $1500 \mathrm{rpm}$ cutter speed for $7 \mathrm{~min}$. Transmission of $20 \%$ is marked by a continuous line. Specific intersections of transmission profiles with this line indicating positions in the cuvette are marked by broken lines. Corresponding photos of the cuvettes after photocentrifugation are also shown. The middle zones with high transmission are clearly visible. Transmission profiles and photos showed refer to the second replicate

$1000 \mathrm{rpm}$ (Fig. 2a), the middle zone had less transmission and less extension. In addition, the proportion of creaming and sedimentation within this zone changed, as indicated by a shift in the broken line (at $116.2 \mathrm{~mm}$ ). The cream layer above and the sedimentation layer below the middle zone expanded accordingly. The higher mechanical input during PC manufacturing favored better fat emulsification with smaller fat globules and increased the stability of the surrounding para-caseinate network (Garimella Purna et al. 2006). The increase in the transmission of the coalesced fat on the surface of the centrifuged PC was less distinct, indicating that it also contained some emulsified fat. 


\subsubsection{Processed cheese with 1.9\% w/w Emulsifying salts}

The PC containing 1.9\% ES was more stable than the PC with $1.0 \%$ ES. Figure 1 presents only the resulting instability index of samples manufactured at $1000 \mathrm{rpm}$ cutter speed. The index was significantly $(p<0.05)$ lower after 7,11 , and 19 min processing time. A processing time of $5 \mathrm{~min}$ was not sufficient to improve the stability in spite of the increased ES content. Results of instability index after 1500 and $3000 \mathrm{rpm}$ cutter were $<0.1$ and not depicted. The PC manufactured at $3000 \mathrm{rpm}$ cutter speed required longer photocentrifugation at $2150 \times g$ to affect emulsion stability. The samples manufactured for $5 \mathrm{~min}$ did not achieve transmission $\geq 20 \%$ until $195 \mathrm{~min}$ or 291 days at $1 \times g$. The later course of the profiles exhibited both zone sedimentation and polydisperse creaming. The zone sedimentation velocity between 200 and $300 \mathrm{~min}$ of centrifugation decreased from 37 to $8 \mu \mathrm{m}$.day ${ }^{-1}$ at $1 \times g$. An increase in processing time up to 7 and 11 min further delayed the formation and extension of this transparent zone, and 19 min of processing resulted in unmeasurable changes in transmission. Extending the processing time at high cutter speed and sufficient content of ES did obviously not result in a defect known as "overcreaming," in which the PC has a short and pudding-like consistency (Guinee et al. 2004). According to the particle size measurements, the small single fat globules (see Table 1), which must have been completely coated by the hydrated para-caseinate, contributed to the high stability of the viscoelastic matrix. The $d_{4,3}$ of the PC manufactured for 5 min was only $2.88 \mu \mathrm{m}$ compared to $12.00 \mu \mathrm{m}$ of the PC with $1.0 \%$ w/w ES in Fig. 2a. This ratio corresponds to the increase in transmission $\geq 20 \%$ during centrifugation of the two samples ( 291 and 33 days at $1 \times g$, resp.).

\section{Conclusions}

The emulsion stability of melted spreadable PC was determined by photocentrifugation at $60{ }^{\circ} \mathrm{C}$. Solid fat globules or clusters contribute to the rigidity of the hydrated paracaseinate matrix in cooled spreadable PC. An increase in product temperature results in liquefaction of the fat and increasing meltability and flowability of the matrix. The degree of these processes is affected by many factors including the content of fat, casein, moisture, and the level of casein hydration. Therefore, photocentrifugation of a spreadable PC with high moisture $(63.5 \%)$ and fat $(40 \%$ in $\mathrm{DM})$ furthers particle movements at $60{ }^{\circ} \mathrm{C}$ distinctly and makes the reactions of the dispersion more clearly. The measurements also reflect the potential of instability that could occur at storage temperatures of $20-30{ }^{\circ} \mathrm{C}$ over a long time. In addition, the results show and explain the development of fat release at heating temperatures.

Under the chosen conditions, an increase in transmission to $\geq 20 \%$ was achieved at different times. The courses of the transmission profiles revealed different particle movements according to the manufacturing conditions and ES content of the PC. Photocentrifugation visualizes the motions of different particle fractions. Zone sedimentation, polydisperse creaming, and sedimentation were identified. Distinct zone sedimentation allowed the calculation of characteristic sedimentation velocities for each PC. All results depend on the adjusted centrifugal force. Insufficient increase in transmission after photocentrifugation at maximum force of a well-emulsified PC 
showed the limits of this method. The new approach of photocentrifugation shows a very high sensitivity proving even little physical changes of the PC matrix. However, this sensitivity restricts the applications to melted spreadable and suboptimal emulsified products. Typical block-type PC would resist the forces during photocentrifugation.

Acknowledgments I thank Norbert Johannsen for manufacturing the processed cheeses and Angelika Thoß and Cornelia Voß for the chemical and physical analysis of the products.

Conflict of interest I have no conflict of interest.

\section{References}

Borcherding K, Hoffmann W, Lorenzen PC, Schrader K (2008) Effect of milk homogenisation and foaming temperature on properties and microstructure of foams from pasteurised whole milk. LWT - Food Sci Technol 41:2036-2043

Brickley CA, Auty MAE, Piriano P, McSweeney PLH (2007) The effect of natural Cheddar cheese and textural properties of the processed cheese therefrom. J Dairy Sci 72:C483-C490

Bunka F, Doudová L, Weiserová E, Cerníková M, Kuchar D, Slavíková S, Nagyová G, Ponízil P, Gruber T, Michálek J (2014) The effect of concentration and composition of ternary emulsifying salts on the textural properties of processed cheese spreads. LWT - Food Sci Technol 58:247-255

Detloff T, Sobisch T, Lerche D (2013) Instability index. Dispersion Letters Technical T4 1-4, ISBN: 978-3944261-29-4

Dimitreli G, Thomareis AS (2008) Effect of chemical composition on the linear viscoelastic properties of spreadable-type processed cheese. J Food Eng 84:368-374

Dimitreli G, Thomareis AS, Smith PG (2005) Effect of emulsifying salts on casein peptization and apparent viscosity of processed cheese. Int J Food Eng 1(4):1-17

El-Bakry M, Duggan E, O'Riordan ED, O'Sullivan M (2010) Small-scale imitation cheese manufacture using a Farinograph. LWT - Food Sci Technol 43:1079-1087

Garimella Purna SK, Pollard A, Metzger LE (2006) Effect of formulation and manufacturing parameters on process cheese food functionality. J Dairy Sci 89:2386-2396

Guinee TP, O'Kennedy BT (2012) Reducing the level of added disodium phosphate alters the chemical and physical properties of processed cheese. Dairy Sci Technol. doi:10.1007/s13594-011-0053-2

Guinee TP, Caric M, Calab M (2004) Pasteurized processed cheese and substitution/imitation cheese products. In: Fox PF, McSweeney PLH, Cogan TM, Guinee TP (eds) Cheese - chemistry, physics and microbiology, vol 2, 3rd edn. Elsevier, Oxford

Hladká K, Randulová Z, Tremlová B, Ponízil P, Mancík P, Cerníková M, Bunka F (2014) The effect of cheese maturity on selected properties of processed cheese spreads. LWT - Food Sci Technol 55:650-656

Hoffmann W, Schrader K (2015) Dispersion analysis of spreadable processed cheese with low content of emulsifying salts by photocentrifugation. Int J Food Sci Technol. doi:10.1111/ijfs. 12725

Lee SK, Buwalda RJ, Euston SR, Foegeding EA, McKenna AB (2003) Changes in the rheology and microstructure of processed cheese during cooking. Lebensm-Wiss Technol 36:339-345

Lee SK, Anema S, Klostermeyer H (2004) The influence of moisture content on the rheological properties of processed cheese spreads. Int J Food Sci Technol 39:736-771

Nagyová G, Bunka F, Salek RN, Cerníková M, Mancik P, Gruber T, Kuchar D (2014) Use of sodium polyphosphates with different linear lengths in the production of spreadable processed cheese. J Dairy Sci 97:111-122

Rayan AA, Kalab M, Ernstrom CA (1980) Microstructure of process cheese. Scan Electron Microsc 3:635643

Schatz K, Hoffmann W, Schrader K, Maurer A (2014) Effect of emulsifying salts containing potassium on the melting properties of block-type dairy cheese analogue. Int J Dairy Technol 67:202-210

Shirashoji N, Jaeggi JJ, Lucey JA (2010) Effect of sodium hexametaphosphate concentration and cooking time on the physicochemical properties of pasteurized process cheese. J Dairy Sci 93:2827-2837

Tobin JT, Fitzsimons SM, Kelly AL, Kelly PM, Auty MAE, Fenelon MA (2010) Microparticulation of mixtures of whey protein and inulin. Int J Dairy Technol 63:32-40 
van Lent K, Le CT, Vanlerberghe B, van der Meeren P (2008) Effect of formulation on the emulsion and whipping properties of recombined dairy cream. Int Dairy J 18:1003-1010

VDLUFA (2003) Methodenbuch Band VI: Chemische, physikalische und mikrobiologische Untersuchungsverfahren für Milch, Milchprodukte und Molkereihilfsstoffe. VDLUFA-Verlag, Bonn

Weiserová E, Doudová L, Galiová L, Zak L, Michálek J, Janis R, Bunka F (2011) The effect of combination of sodium phosphates in binary mixtures on selected texture parameters of processed cheese spreads. Int Dairy J 21:970-986 